\title{
Problems related to acute respiratory infection among under-5 children in Sorong, West Papua: A community diagnosis approach
}

\author{
Edo Prabudi Thamrin, ${ }^{1}$ Risma Kristi Utami, ${ }^{1}$ Fabianto Santoso, ${ }^{1}$ Ayu Ashari Thamrin, ${ }^{2}$ Siti Syahral Ain, ${ }^{2}$ \\ Trevino Aristarkus Pakasi ${ }^{3,4, *}$ \\ ${ }^{1}$ Department of Community Medicine, Faculty of Medicine, Universitas Indonesia, Jakarta, Indonesia \\ ${ }^{2}$ Department of Community Medicine, Faculty of Medicine, Universitas Papua, Sorong, Indonesia \\ ${ }^{3}$ Department of Community Medicine, Faculty of Medicine, Universitas Indonesia, Jakarta, Indonesia \\ ${ }^{4}$ Center for Research and Integrated Development of Tropical Health and Infectious Disease (CRID \\ TROPHID), Universitas Indonesia, Jakarta, Indonesia
}

\section{Submitted: 24 June 2019 Revised: 13 November 2019 Accepted: 2 December 2019}

\begin{abstract}
Acute respiratory infections (ARIs) are the leading cause of morbidity and mortality in children under five years, with a periodic prevalence of $25.9 \%$ in West Papua (2013). This study aims to explain the factors associated with ARIs in under-5 children in Sorong District, West Papua. This cross-sectional study was conducted in two districts, where trained medical students interviewed 135 mothers/caregivers by using a structured questionnaire and interviewed cadres and health workers for qualitative observation. About $85.5 \%$ of respondents stated that their children had ARIs in the previous two weeks $(n=135)$, much higher than the data from Sorong District Health Office, which only reached 24.63\%. Dominant risk factors were large household size, smoking at home, and improper handwashing habits. Only half of the respondents went to a physician in a primary care facility. Nearly half of the respondents had difficulty in accessing the facility. The majority of caregivers used over-the-counter or traditional medicine. Around $70 \%$ of respondents in Makbon Subdistrict did nothing to prevent the transmission of ARIs among children. ARIs remains a massive problem in the Sorong District. We need to educate the mothers/caregivers about the rational use of medicine and the prevention of ARIs, and also advocate for better access to clean water, sanitation, and healthcare facilities.
\end{abstract}

KEYWORDS acute respiratory infection; toddlers; West Papua

\section{Introduction}

Acute respiratory infections (ARIs) includes all infections in the upper and lower respiratory tract. This infection is a significant cause of morbidity and mortality in children under five years old (toddlers) in developing countries. ${ }^{1}$ Considering the fact, it turns out that many respiratory infections are pneumonia, which has a high risk of mortality. The Ministry of Health of the Republic of Indonesia through Basic Health Research (Riskesdas) reported the periodic prevalence of ARIs in Indonesia, which reached $25.5 \%$ in 2007 and was still at $25.0 \%$ in 2013. This prevalence varies between all provinces, with the West Papua Province reaching 25.9\%. The age group of 1-4 years had the highest rate of ARI in Indonesia, with a prevalence of $25.8 \%$. The periodic prevalence of pneumonia in Indonesia has decreased from $2.1 \%$ in 2007 to $1.8 \%$ in 2013, with the West Papua Province below at $1.3 \%$.

\footnotetext{
*Corresponding author: Trevino Aristarkus Pakasi

Department of Community Medicine, Faculty of Medicine, Universitas Indonesia, Pegangsaan Timur No. 16, Jakarta, 10320, Indonesia

E-mail: tpakasi@yahoo.com
} 
The integrated management may influence years of reduction in morbidity and mortality in child disease programs that have been started in primary care more than a decade ago.

ARIs are still the most common diseases in Sorong District, West Papua Province, for many years. Data from the Sorong District Health Office showed ARIs was ranked first in the list of 10 most common diseases in 2012-2014, with prevalence ranging from $25-27 \%$. This fact needs to be investigated further both from the implementation of the program in the government primary health center (PHC) as well as other factors such as the environment and culture that may influence case finding and management of ARIs.

The purpose of this study is to explain the factors that influence ARIs in children under five in Sorong District, West Papua Province.

\section{Methods}

\subsection{Study design}

This study is a cross-sectional study that combines quantitative and qualitative findings conducted in two districts in Sorong District.

\subsection{Research subjects and data collection}

Data collection was conducted quantitatively and qualitatively in two districts (Makbon and Klamono Subdistricts) in May and June 2015. The two districts were selected based on the ease of permit for the survey. A total of 135 quantitative survey respondents who were housewives or caregivers were selected from households with children under five and interviewed based on a structured questionnaire that included demographics, caregiver behavior, risk factors for ARIs, and access to health facilities. Interviewers are previously trained medical students for the purpose of the study.

Qualitative methods were used to explore further the problems that exist in the community and health services, concerning the regional data about demographics, health services, and PHC evaluation reports. The authors of this study interviewed the head of the PHCs, health cadres, patients, and officers from the District Health Office. In particular, interviews were directed to find out more about problems related to access to health facilities, patterns of self-medication behavior, and established health services. In each interview, one author performed as the interviewer and another as the notetaker. After the interview, the authors compiled the information and assessed all field notes for themes across different backgrounds of the key informants.

\subsection{Data analysis}

Quantitative findings were analyzed descriptively, based on demographic backgrounds, presence of $A R I$, and its risk factors. Qualitative findings were used to explain quantitative findings more in-depth. The authors assessed the field notes for striking keywords or themes to find a pattern or matrix of how subjects would respond to the symptoms of ARIs against their demographic background.

\subsection{Research ethics}

The Ethics Committee of the Faculty of Medicine, Universitas Indonesia has approved research ethics.

\section{Results}

A total of 135 women respondents from Makbon and Klamono Subdistricts were interviewed to obtain quantitative data, with $16.3 \%$ of them from Klawana Village, $11.1 \%$ from Klalomon Village, 43.0\% from Klamono Village, 25.9\% from Makbon Village, and 3.7\% from Wariau Village. The demographic characteristics of the respondents are summarized in Table 1.

From Table 1, nearly half of caregivers were found to have a quite good academic background, namely completing high school or higher education (28.9\% and $20.0 \%$, respectively). However, many are unemployed or become farmers ( $36.6 \%$ and $26.1 \%$, respectively). An officer from the District Health Office gave government data showing that only $24.9 \%$ of women from the labor force in the district have completed high school or higher education. ${ }^{2}$ 
Table 1. Demographic characteristics of patients

\begin{tabular}{lc}
\hline Variable & $\mathrm{n}(\%)$ \\
\hline Age group ( $\mathrm{n}=131)$ & $14(10.7)$ \\
$\leq 20$ years & $47(35.9)$ \\
$21-30$ years & $53(40.5)$ \\
$31-40$ years & $17(13)$ \\
$>40$ years & \\
Academic background ( $\mathrm{n}=135)$ & $12(8.9)$ \\
Never going to school & $10(7.4)$ \\
Not completing elementary school (SD) & $16(11.9)$ \\
Completed elementary school (SD) & $31(23)$ \\
Completed junior high school (SMP) & $39(28.9)$ \\
Completed high school (SMA) & $27(20.0)$ \\
Completed higher education & \\
Occupation ( $\mathrm{n}=134)$ & $49(36.6)$ \\
Unemployed & $22(16.4)$ \\
Civil servants (PNS) & $7(5.2)$ \\
Private employees & $1(0.7)$ \\
Students & $6(4.5)$ \\
Traders & $35(26.1)$ \\
Farmers & $1(0.7)$ \\
Laborers & $1(0.7)$ \\
Fishermen & $12(9.0)$ \\
Others & \\
Household income (per month) ( $=126)$ & $5(4)$ \\
No regular income & $45(35.7)$ \\
Less than IDR 500.000 & $25(19.8)$ \\
IDR 500.000-1.000.000 & $46(36.5)$ \\
IDR 1.000.001-5.000.000 & $5(4)$ \\
\hline & \\
\hline IDR 5.000.000 & \\
\hline
\end{tabular}

The different population that does not include housewives may cause discrepancy, although this discrepancy may also give an idea that our subjects are more educated than the general population. Different businesses between the districts may influence the high education background in the community since the Klamono Subdistrict had oil refinery. Nearly $40 \%$ of respondents have low household income (less than IDR 500,000 per month).
Table 2 shows the proportion of children under five with ARIs that was still high. More than half of the respondents reported symptoms of ARIs (cough or runny nose) within two weeks before data collection (85.5\%). Self-treatment behavior before seeking medical treatment was found to be high. Many of the caregivers self-treat their toddlers with over-the-counter or traditional medicines or tell their children to rest and adjust their children's nutritional intake. The most 
Table 2. Caregiver behavior of children under five with ARIs

\begin{tabular}{ll}
\hline Variable & $\mathbf{n}(\%)$ \\
\hline Children had ARIs within two weeks before data collection ( $\mathrm{n}=135)$ & $112(85.5)$ \\
Children with ARIs during the data collection ( $\mathrm{n}=135)$ & $71(53.4)$ \\
Self-treatment behavior before seeking medical care $(\mathrm{n}=104)$ & \\
Over-the-counter medicine & $38(36.5)$ \\
Traditional medicine & $22(21.2)$ \\
Rest & $28(26.9)$ \\
Rest with adequate nutritional intake & $15(14.4)$ \\
Others & $1(1.0)$ \\
Medical care-seeking behavior ( $\mathrm{n}=129)$ & \\
PHC physicians & $69(53.5)$ \\
Private physicians & $14(10.9)$ \\
Hospitals & $3(2.3)$ \\
Midwives & $11(8.6)$ \\
Nurses & $34(25.6)$ \\
Others & $4(3.1)$ \\
Reason to seek medical care ( $\mathrm{n}=127)$ & \\
Cough & $30(23.6)$ \\
Runny nose & $7(5.5)$ \\
Cough and runny nose & $58(45.7)$ \\
Additional symptoms besides cough or runny nose & $22(17.3)$ \\
No improvement with self-treatment & $10(7.9)$ \\
Prevention of disease transmission ( $\mathrm{n}=35)$ & \\
Cover the mouth and nose & $7(21.2)$ \\
Sleep in a separate room & $3(9.1)$ \\
Do nothing & $23(69.7)$ \\
\hline
\end{tabular}

commonly used traditional medicine is a mixture of lime and soy sauce, which has been passed down from generation to generation. Other traditional medicines are boiled leaves of bitter melon (Momordica charantia).

In general, caregivers will bring their toddlers to medical care when the child shows symptoms of ARIs. However, there were $17.3 \%$ of respondents who will start considering bringing their toddlers for treatment when there were additional symptoms other than cough and runny nose and $7.9 \%$ of respondents who did it when there was no symptom improvement with self-medication.
Also, only around half of the respondents seek medical care at the PHC, while the rest go to private practices, hospitals, midwives, nurses, or others.

From interviews with several caregivers, they said that the causes of ARIs include viruses, inhaled dust, and rain showers. In general, they also know that ARIs can be transmitted through the air. However, from the survey, about $70 \%$ of respondents in the Makbon Subdistrict did nothing to prevent the spread of ARIs. Regarding environmental factors that can affect the occurrence of ARIs, rain is the thing most often expressed by caregivers.

Table 3 shows the ARIs risk factors in 
Table 3. Risk factors of ARIs

\begin{tabular}{|c|c|c|c|c|}
\hline \multirow{2}{*}{ Variable } & \multicolumn{2}{|c|}{$\begin{array}{l}\text { ARIs in the past } \\
\text { two weeks }(n, \%)\end{array}$} & \multirow[t]{2}{*}{$P$} & \multirow{2}{*}{$\begin{array}{l}\text { Prevalence } \\
\text { ratio }\end{array}$} \\
\hline & Yes & No & & \\
\hline \multicolumn{5}{|c|}{ Number of household members $(n=135)$} \\
\hline$\leq 4$ & $33(82.5)$ & $7(17.5)$ & 0.519 & 0.83 \\
\hline$>4$ & $79(86.8)$ & $12(13.2)$ & & \\
\hline \multicolumn{5}{|l|}{ Smoking at home $(n=134)$} \\
\hline Yes & $97(87.4)$ & $14(12.6)$ & 0.301 & 1.1 \\
\hline No & $15(78.9)$ & $4(21.1)$ & & \\
\hline \multicolumn{5}{|c|}{ Proper handwashing behavior of caregivers $(n=130)$} \\
\hline Yes & $43(81.1)$ & 10 (18.9) & 0.311 & 0.81 \\
\hline No & $64(87.7)$ & $9(12.3)$ & & \\
\hline \multicolumn{5}{|c|}{ Caregivers teach children how to wash their hands $(n=121)$} \\
\hline Yes & $93(85.3)$ & $16(14.7)$ & 0.596 & 0.85 \\
\hline No & $8(100.0)$ & $0(0.0)$ & & \\
\hline
\end{tabular}

respondents. More than two-thirds of respondents have $>4$ family members who live together at home. Also, as many as $85 \%$ of respondents said there was smoking behavior at home, either done by parents or other family members. Regarding hand washing habits, $93.1 \%$ of respondents taught their children how to wash their hands, even though almost $60 \%$ of respondents did not know the proper method of handwashing. However, none of the risk factors were significant to the prevalence of ARIs in the community. The prevalence of ARIs was slightly higher in respondents with indoor air pollution, but not in respondents with overcrowded homes and poor hand hygiene.

Regarding access to health facilities, Table 4 shows that although more than half of the respondents $(62.2 \%)$ did not need to spend transportation fee to health care facilities, almost half (47.8\%) had difficulty reaching health facilities.

Problems with access to health facilities were found in respondents living far from the PHC. In the two districts that were surveyed, Klamono Health Center was still close enough to the respondents interviewed, whereas, in the Makbon Subdistrict, there were respondents from two villages far from the Makbon Health Center $(2-5 \mathrm{~km})$. As many as
$40 \%$ of respondents walked to the $\mathrm{PHC}$, and the rest mostly used motorcycle taxis $(28.6 \%)$ or private transportation (25.6\%). However, based on the narrative of health staff in both PHCs, some villages can only be reached by boat because they need to cross the river. The Head of the Klamono Health Center said, "The village farthest from here must be reached through the sea, by using a longboat for about three hours." Similar conditions were found in the Makbon Subdistrict. "Our village has to be reached through the sea," said the Head of Makbon Health Center. Estimates of the distance from the PHCs in the Klamono and Makbon Subdistricts to the respondent's living area can be seen in Figure 1 and Figure 2.

To reach remote villages, both PHCs make regular visits to the villages once a month in a program called "Mobile Health Center" (Pusling). Activities carried out during the Pusling included Maternal and Child Health (KIA) program, outpatient care, Family Planning (KB), health screening, and anthropometric measurements of children under five at the Integrated Care Post (Posyandu).

\section{Discussion}

Based on Basic Health Survey published by the 
Table 4. Access to health facilities

\begin{tabular}{ll}
\hline \multicolumn{1}{c}{ Variable } & $\mathbf{n}(\%)$ \\
\hline Having difficulty reaching health facilities $(\mathrm{n}=134)$ & \\
Yes & $64(47.8)$ \\
No & $70(52.2)$ \\
Mode of transportation to health facilities $(\mathrm{n}=133)$ & \\
On foot & $54(40.6)$ \\
Motorcycle taxi & $38(28.6)$ \\
Public transport & $4(3.0)$ \\
Private transportation & $34(25.6)$ \\
Walk or using a motorcycle taxi & $1(0.8)$ \\
Walk or using private transportation & $2(1.5)$ \\
Travel time to health facilities $(\mathrm{n}=131)$ & \\
$\leq 15$ minutes & $84(64.1)$ \\
$16-30$ minutes & $25(19.1)$ \\
$31-45$ minutes & $1(0.8)$ \\
$46-60$ minutes & $16(12.2)$ \\
$61-120$ minutes & $5(3.8)$ \\
$>120$ minutes & $0(0.0)$ \\
Round-trip transportation costs $(n=135)$ & \\
No fees & $84(62.2)$ \\
IDR 5,000 & $1(0.7)$ \\
IDR 10,000 & $9(6.7)$ \\
IDR 15,000 & $1(0.7)$ \\
IDR 20,000 & $34(25.2)$ \\
IDR 30,000 & $4(3.0)$ \\
IDR 50,000 & $2(1.5)$ \\
\hline
\end{tabular}

Ministry of Health of the Republic of Indonesia, West Papua is one of the provinces with a high periodic prevalence of ARIs. ${ }^{1}$ Data from the Sorong District Health Office in 2014 showed the prevalence of ARIs as much as $24.63 \%$. The results of this study show that the proportion of children under five who experience ARIs symptoms in the past two weeks as much as $85.5 \%$, and during the data collection was $53.4 \%$. The symptoms most often complained of by toddlers based on caregiver reports are coughing and runny nose.

Children under five are indeed the most vulnerable group to experience ARIs, where several other studies also indicate this condition. ${ }^{3-5}$ They are more susceptible to infection because their immune systems are immature. ${ }^{6}$ Children are also known to spread the virus in longer duration than adults. $^{7}$

Environmental factors also play a role, with caregivers interviewed saying that ARIs are more common during the rainy season. This finding is consistent with other studies that show an association between temperature and humidity with the ARIs transmission. ${ }^{8-11}$ Reduced duration of skin exposure to the sun during the rainy season also reduces vitamin $D$ intake, and vitamin $D$ 


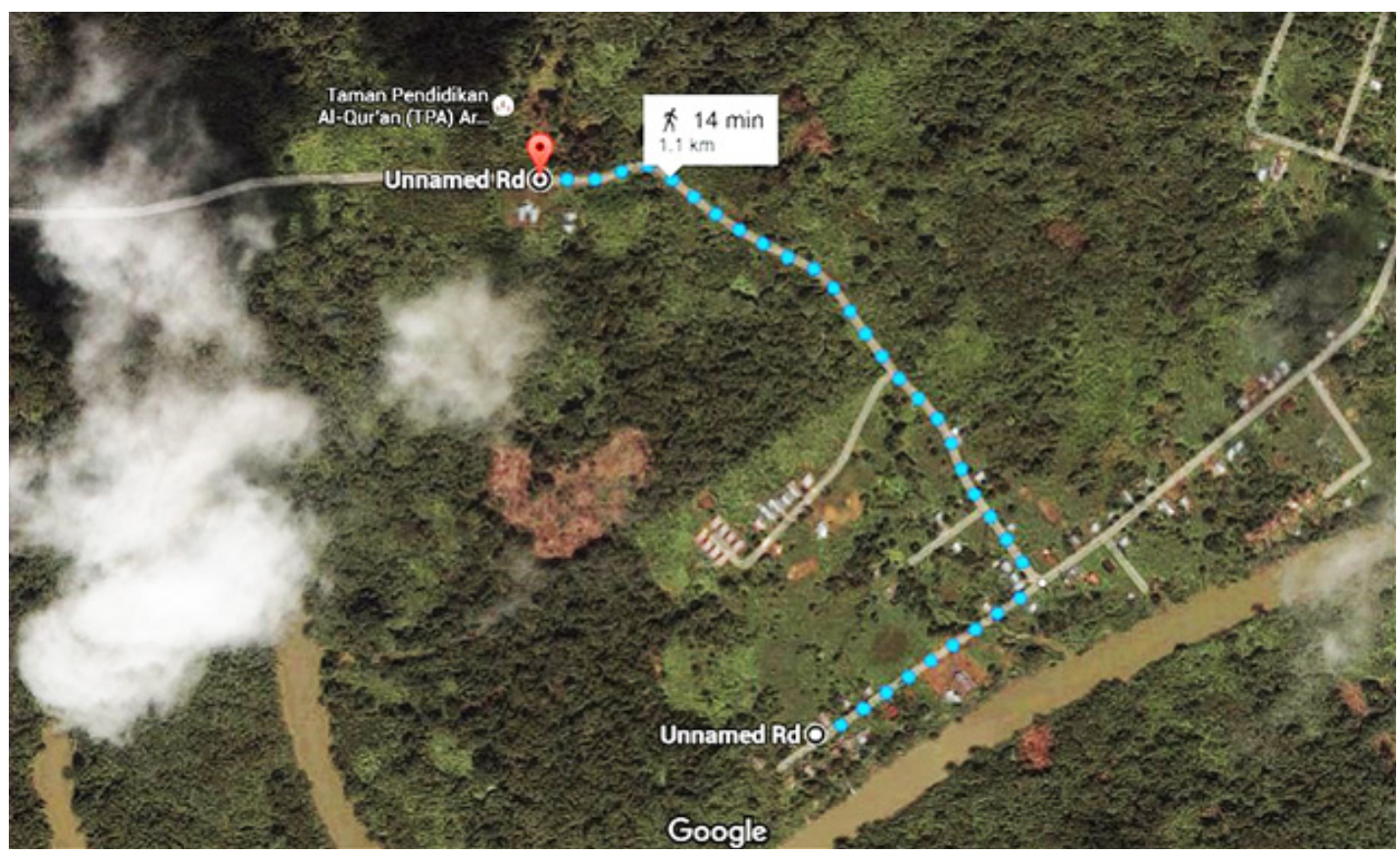

Figure 1. Estimated distance from the PHC to Respondents' Living Area in the Klamono Subdistrict (Source: Google Maps)

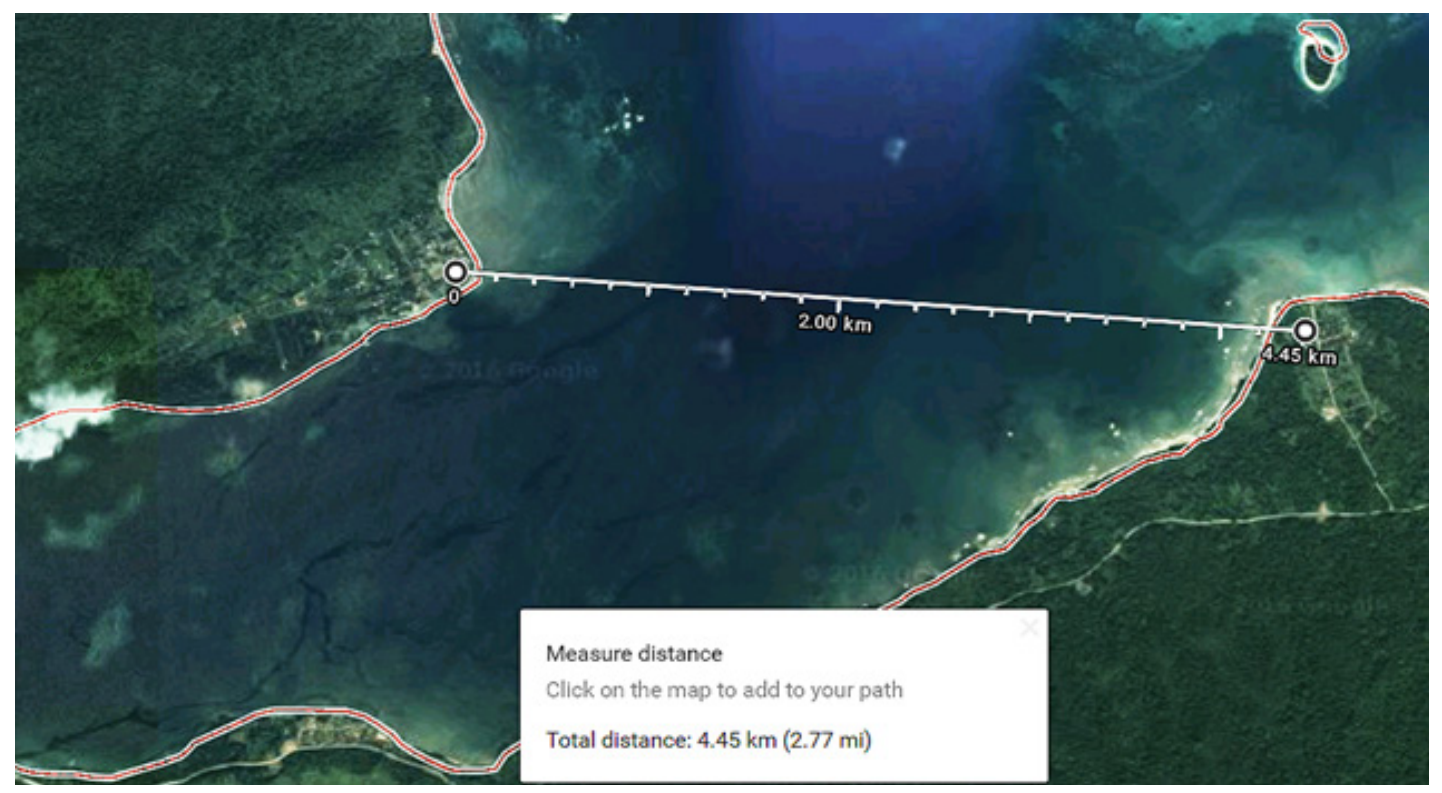

Figure 2. Estimated distance from the PHC to Respondents' Living Area in the Makbon Subdistrict (Source: Google Maps)

deficiency has been known to disrupt the body's antimicrobial system, thus increasing the risk of ARIs. ${ }^{12}$ However, this study only collected data during the rainy season, so there is no data on the proportion of inter-season ARIs proportions.

The risk factors associated with ARIs found in this study included an overcrowded home, smoking behavior at home, and improper handwashing habit. We found that the prevalence of ARIs was higher in respondents with indoor air pollution. Other studies in Papua, ${ }^{13}$ Aceh, ${ }^{9}$ Java,${ }^{10,11}$, and Kalimantan ${ }^{14,15}$ highlighted the dangers of overcrowded home and indoor air pollution, including smoking habits at home. The number of 
smokers was said to be proportional to the number of sufferers of health problems. Based on studies in China, ${ }^{16}$ India, ${ }^{17}$, and Malawi, ${ }^{4}$ an overcrowded home and smoking habit at home increases the risk of ARIs in children under five. Exposure to tobacco smoke is known to cause ill health and mortality in children, especially among those under five years of age.

Another factor that plays a role in the transmission of ARIs was children's behavior who are less accustomed to maintaining hand hygiene so that they can get the infection from the people around them. This factor is more dominant in toddlers aged $>2$ years since they have actively begun to interact with their surroundings and are more exposed to the unhygienic environment, as documented by a study in Aceh. ${ }^{18}$ In this study, many respondents did not have the proper habit of washing their hands so they could not teach their children how to wash their hands properly.

An external factor that can affect the high proportion of ARIs in children under five is difficult accessibility to health facilities. Nearly half of the respondents (47.8\%) had difficulty going to health facilities, and only around half of the respondents (53.5\%) went to the primary care physician at the PHC for treatment. Residents who live far from health facilities also experienced this problem, for example, from areas that can be only reached by boat. This limited access to healthcare prevents the population from getting appropriate management for their illness, as also noted in a study by Cox, et al. ${ }^{4}$ A study in Australia shows that rural dwellers have a significantly lower likelihood of reporting ARIs compared to urban dwellers. ${ }^{5}$

The caregivers' behavior, when their toddlers have ARIs, is also a factor that influences the high proportion of ARIs. Self-treatment behavior was found to be quite high. More than half of the respondents use over-the-counter and traditional medicines, even though $83.7 \%$ of caregivers are well educated. This finding is different from the study in Pakistan, where $97 \%$ of caregivers with an urban background were well educated, and self-medication behavior was only $6 \% \cdot{ }^{19} \mathrm{~A}$ similar study in Hyderabad, India, shows that around 29\% of mothers with mostly good academic background tried to manage their child with cough/fever syrup, probably due to limitations in the affordability and accessibility of primary healthcare. ${ }^{20}$ Our respondents sought medical treatment when their toddlers showed symptoms of coughing and runny nose, with only $7.9 \%$ of respondents seeking medical treatment when their child's condition did not improve. This finding was a very positive factor that might be influenced by mostly high education background of the caregivers, with similar findings showed in the study by Challa et al. ${ }^{20}$ However, although many respondents sought medical care, only half of them went to the physician at the PHC. The fact that most respondents were eager to seek medical treatment despite having difficulty in accessing a primary health facility showed the potential for community-based treatment training for ARIs as performed and documented by Cahyaningsih et al. in Bandung, West Java. ${ }^{21}$

Regarding prevention, the caregivers' awareness level is still relatively low, despite their mostly good academic background. In Makbon Subdistrict, $70 \%$ of respondents did nothing to prevent the spread of ARIs. This behavior causes ARIs to be easily transmitted to other children. Higher education tends to affect the knowledge and decision-making process, as noted in a study by Anggraini et al. ${ }^{8}$ In the study, only $7 \%$ of parents with high education level had an unhealthy behavior, in contrast with the percentage of $41 \%$ in those with lower education level. However, this was not what we founded in Sorong District. In Sumatera, a study by Handayuni, et al. found that the knowledge of ARIs and the related preventive efforts were still lacking among mothers, probably due to misperception about the severity of ARIs. ${ }^{22}$ However, it did not specify their academic background.

Limitations of this study include the criteria used to diagnose ARIs. In this study, only two main symptoms of ARIs were identified, namely coughing and runny nose. Also, the selection of respondents did not cover areas that are far from the PHCs, but 
still within $5 \mathrm{~km}$ from the PHCs, so the findings in this study may not represent the entire region. The short duration of the study also does not make it possible to assess inter-season effects on the proportion of ARIs.

\section{Conclusion}

Factors that may affect the high rates of ARIs in children under five in Sorong District consist of overcrowding, smoking at home, improper handwashing habit, difficult access to healthcare facilities, cultural factors related to irrational treatment, and the lack of knowledge about the prevention of disease transmission. However, different cultural and environmental factors should be considered before applying the results for other districts in West Papua. Dissemination of information for mothers and caregivers is necessary: first, regarding the proper use of overthe-counter drugs, including antibiotics that can be bought without a prescription, so that it may not harm their toddlers; second, about the transmission of the disease so that they can take appropriate precautions. Advocation for better access to clean water and sanitation and better access to healthcare facilities is also necessary.

\section{Acknowledgement}

The author states that there is no conflict of interest in conducting the research. The author appreciates the support of PT. Unilever Indonesia for research funding channeled through CRID TROPHID Universitas Indonesia.

The authors would like to thank the Sorong District Health Office, doctors, and other health staff at Makbon Health Center and Klamono Health Center, as well as health cadres in the involved villages for their assistance in carrying out this research.

The author would like to thank his partner, Mulyansyah, a sociologist from Sorong Muhammadiyah University, and Hermanto, Rector of Sorong Muhammadiyah University, for his assistance in providing input regarding the culture of indigenous Papuans in Sorong.

\section{References}

1. Riset Kesehatan Dasar 2013. Jakarta: Badan Penelitian dan Pengembangan Kementerian Kesehatan Republik Indonesia; 2013.

2. Kabupaten Sorong dalam Angka 2014. Sorong: Badan Pusat Statistik Kabupaten Sorong; 2014.

3. Krishnan A, Amarchand R, Gupta V, Lafond KE, Suliankatchi RA, Saha $S$, et al. Epidemiology of acute respiratory infections in children preliminary results of a cohort in a rural north Indian community. BMC Infect Dis. 2015;15 (1):462.

4. Cox M, Rose L, Kalua K, de Wildt G, Bailey R, Hart J. The prevalence and risk factors for acute respiratory infections in children aged 0-59 months in rural Malawi: A cross-sectional study. Influenza Other Respir Viruses. 2017 (6):489-96.

5. Chen $Y$, Williams $E$, Kirk M. Risk factors for acute respiratory infection in the Australian community. PLoS ONE. 2014;9(7):e101440.

6. Kinanthi CA, Notobroto HB, Martini S. Determinants of Acute Respiratory Infections Among Child Under Five Years in Surabaya. Health Notions. 2018;2(3):380-2.

7. Bridges $C$, Kuehnert M, Hall C. Transmission of influenza: implications for control in health care settings. Clin Infect Dis. 2003;37:1094101.

8. Anggraini $T$, Mudigdo A, Soemanto RB. Association Between the Socioeconomic Factors, Healthy Home, and Healthy Behavior Among Parents of Toddler with Acute Respiratory Infection in Kediri, Indonesia. J Epidemiol Public Health. 2016;1(1):66-74.

9. Sofia S. Faktor Risiko Lingkungan dengan Kejadian ISPA pada Balita Di Wilayah Kerja Puskesmas Ingin Jaya Kabupaten Aceh Besar. AcTion Aceh Nutr J. 2017;2(1):43-50.

10. Sari DA, Budiyono B, Darundiati YH. Hubungan antara Kualitas Udara dalam Ruang dengan Kejadian Pneumonia pada Bayi di Wilayah Kerja Puskesmas Bandarharjo Kota Semarang. 
Media Kesehatan Masyarakat Indonesia. 2019;18(3):12-8.

11. Fahdiyani R, Raksanagara AS, Sukandar $H$. Influence of Household Environment and Maternal Behaviors to Upper Respiratory Infection among Toddlers. Kesmas Natl Public Health J. 2016;10(3):120-6.

12. Narang GS, Arora S, Kukreja S, Shifali D. Association of Vitamin D Deficiency with Acute Lower Respiratory Infection in Toddlers. J Nepal Paediatr Soc. 2016;36(1):14-6.

13. Gainau E, Rantetampang A, Pongtiku A, Mallongi A. Factors Influence of Acute Respiratory Infection Incidence to Child Under Five Years in Timika Jaya Health Primary Mimika District. International Journal of Science \& Healthcare Research. 2019;4(1).

14. Hidayah N, Rahman TA, Salmarini DD. Household Environment Factors Associated With Acute Respiratory Infection (Ari) Among Under-Five Children. In Atlantis Press; 2017 [cited 2019 Nov 17]. Available from: https:// www.atlantis-press.com/proceedings/ smichs-17/25886852

15. Meilantika $A D$, Hadisaputro $S$, Mexitalia $M$, Sakundarno M, Rahardjani KB. Study of Family Behavior that At Risk For Pneumonia in Under Five Children in Mempawah District. Health Notions. 2018;2(4):490-3.

16. Huai $Y$, Guan $X$, Liu S, Uyeki TM, Jiang $H$, Klena $\mathrm{J}$, et al. Clinical characteristics and factors associated with severe acute respiratory infection and influenza among children in
Jingzhou, China. Influenza Other Respir Viruses. 2017;11(2):148-56.

17. Kumar G, Majumdar A, Kumar V, Naik B, Selvaraj $K$, Balajee K. Prevalence of acute respiratory infection among under-five children in urban and rural areas of puducherry, India. Journal of Natural Science, Biology and Medicine. 2015;6(1):1-6.

18. Safitri F, Hayati R, Marniati. Analysis of risk factors for acute respiratory tract infections (ARI) of Toddlers in Ingin Jaya community health centre of Aceh Besar district. AIP Conf Proc. 2017;1885(1):020037.

19. Bham SQ, Saeed F, Shah MA. Knowledge, Attitude, and Practice of mothers on acute respiratory infection in children under five years. Pak J Med Sci. 2016;32(6):1557-61.

20. Challa S, Krosuri V. Danger signs of acute respiratory tract infections in under-five children: awareness among mothers in the urban slums of Hyderabad, its relation to treatment seeking behaviour. Int J Community Med Public Health. 2018;6(1):190-6.

21. Cahyaningsih $H$, Kusmiati $S$, Husni A. The Effectiveness of Treatment Training for Children with Acute Respiratory Tract Infection to Mothers of Toddlers in Bandung Indonesian. Open J Nurs. 2017;7(7):759-69.

22. Handayuni L, Alfian AR, Amran A, Razak A. Knowledge of mother about the household environment againt acute respiratory infection in Padang Pasir: A literature study. IOP Conf Ser Earth Environ Sci. 2019;314(1):012076. 